\title{
A TEORIA DAS RESTRIÇÕES APLICADA NO SETOR PÚBLICO: UMA REVISÃO DA LITERATURA
}

THE THEORY OF CONSTRAINTS APPLIED IN THE PUBLIC SECTOR: A LITERATURE REVIEW

Recebido em: 06 jun. 2020

Aprovado em: 05 dez. 2020

Versão do autor aceita publicada online: 05 dez. 2020

Publicado online: 04 jun. 2021

Como citar esse artigo - American Psychological Association (APA):

Santos, S. T., Pereira, T. F., \& Santos, A. C. O. (2022, jul./set.). A Teoria das Restrições aplicada no setor público: uma revisão da literatura. Exacta. 20(3), 786-809.

https://doi.org/10.5585/exactaep.2021.17369.

Submeta seu artigo para este periódico 7

Dados Crossmark 


\title{
A TEORIA DAS RESTRIÇÕES APLICADA NO SETOR PÚBLICO: UMA REVISÃO DA LITERATURA
}

\author{
THE THEORY OF CONSTRAINTS APPLIED IN THE PUBLIC SECTOR: A LITERATURE \\ REVIEW
}

iD Scheirla Teixeira Santos ${ }^{1}$

iD Tábata Fernandes Pereira ${ }^{2}$

Ana Carolina Oliveira Santos ${ }^{3}$

\author{
${ }^{1}$ Mestre \\ Universidade Federal de Itajubá - UNIFEI \\ Itabira - MG, Brasil \\ scheirlasantos@unifei.edu.br \\ 2 Doutora \\ Universidade Federal de Itajubá - UNIFEI \\ Itabira - MG, Brasil \\ tabatafp@unifei.edu.br \\ 3 Doutora \\ Universidade Federal de Itajubá - UNIFEI \\ Itabira - MG, Brasil \\ anasantos@unifei.edu.br
}

Recebido em: 06 jun. 2020

Aprovado em: 05 dez. 2020
Resumo: Considerando a importância da Teoria das Restrições para as organizações privadas, o objetivo deste estudo é realizar um levantamento na literatura, para identificar como a utilização dessa ferramenta impacta também nas instituições públicas. O método utilizado consiste em uma Revisão Sistemática da Literatura abrangendo as pesquisas, nacionais e internacionais, publicadas sobre o tema entre 2009 e 2019. O estudo contribui para a teoria com o resgate dos trabalhos que abordaram a metodologia nas especificidades do serviço público, sintetizando a evidência disponível na literatura. Como contribuição prática, o estudo apresenta um instrumento de diagnóstico pode auxiliar profissionais e pesquisadores no seu cotidiano de trabalho e aprimoramento das operações das instituições. Por fim, a contribuição para a sociedade, está na demonstração de possibilidade de adoção de um mecanismo de melhoria contínua para os processos e estratégias dos órgãos públicos, que por sua vez reflete no melhor atendimento aos anseios da sociedade.

Palavras-chave: Gargalos. Teoria das Restrições. Administração Pública.

Abstract: Considering the importance of the Theory of Restrictions for private organizations, the objective of this study is to carry out a survey in the literature to identify how the use of this tool also impacts public institutions. The method used consists of a Literature Systematic Review covering national and international research published on the subject between the years 2009 and 2019. The study contributes to the literature with the rescue of works that addressed the methodology in the specificities of the public service. From a practical point of view, it presents a diagnostic tool that has worked effectively in improving the operations of the institutions. Finally, the study is considered relevant for society, given the possibility of discoveries capable of bringing general social benefits as a mechanism of continuous improvement for the processes and strategies of public agencies, which in turn reflects in better service to society's wishes.

Keywords: Bottlenecks. Theory of Constraints. Public. Management. 


\section{Introdução}

A Constituição da República Federativa do Brasil (1998/2001) estabelece que a administração pública tem por princípio o exercício de suas competências de forma eficiente, com qualidade, primando pela adoção de critérios e ferramentas necessários para melhor utilização possível dos recursos públicos, evitando desperdícios e garantindo maior rentabilidade social (Constituição do Brasil, 1988).

Nesse contexto, de acordo com Santos (2018), em decorrência das diversas crises iniciadas no final do último século, a administração pública foi induzida a implementar reformas administrativas que buscam consolidar boas práticas derivadas do setor privado, com a finalidade de se adequar às demandas contemporâneas por meio da redefinição das funções do Estado.

Além disso, para Andrade (2012) a pressão do mercado, por uma elevada carga de atividades e práticas eficientes das universidades, e também da própria sociedade por redução de custos e aumento dos níveis de serviço prestados pelas iniciativas públicas, tem levado à importância da eficiência na gestão do Estado, o que vai de encontro com as competências estabelecidas pela Constituição Federal.

Adicionalmente, um recorte temporal nos movimentos de reforma do estado evidencia que, com a intensificação da democratização a partir de 1985, o serviço público brasileiro vem passando por várias e profundas transformações, desde a reforma gerencial de meados dos anos 1990 e, mais recentemente, pela reestruturação do aparelho de Estado sob o discurso da retomada do desenvolvimento nacional (Cavalcante, Camões, Cunha, \& Severo, 2017).

Dessa forma, nesta busca para alcançar a eficiência na prestação dos serviços, tem-se notado um esforço dos agentes públicos quanto à implementação de técnicas e ferramentas da qualidade no dia-a-dia das instituições, para identificar os gargalos existentes nas diferentes áreas de atuação.

Dentre os inúmeros esforços que vem sendo dispendidos pelas instituições na busca da melhoria da eficiência de seus processos, destaca-se a Teoria das Restrições (Theory of Constraints TOC), considerada como método de identificação, análise e solução de problema, através do processo de raciocínio que responde a três questões: O que mudar? Para que mudar? Como causar a mudança? (Araújo, 2004). Filosofia essa que permite a reflexão e análise dos processos institucionais numa abordagem internamente mais crítica.

Ainda segundo Knaggs, Pollard e Wang (2012), a TOC é um método baseado em Sócrates, voltado para a mudança da gestão com um foco consistente sobre as causas de raiz dos problemas identificados, continuamente fazendo pergunta sobre por que as coisas existem como elas são. Logo, as soluções surgem devidamente enquadradas para a identificação das restrições primárias que impedem o alcance das metas propostas. 
As principais vantagens de aplicação da TOC no setor público estão no fato de que a ferramenta pode trazer uma abordagem mais organizada às operações e, como isso, propiciar aos gestores direcionar esforços e ações para as restrições dos processos, o que, por consequência, contribuirá com a melhoria dos processos (Knaggs et al., 2012).

Desse forma, considerando seu potencial de ajuste para melhoria dos processos de trabalho, a TOC apresenta-se como um método possível para aprimorar os processos e atividades desenvolvidos no setor público, de modo a elevar a eficiência dos serviços prestados (Knaggs et al., 2012), fator esse que vem de encontro com o estilo de administração pública que se esperar ter nas instituições.

Sendo assim, considerando toda a contextualização aqui apresentada e a importância da TOC para a melhoria dos processos, este artigo tem como objetivo realizar uma Revisão Sistemática da Literatura, a fim de analisar as pesquisas feitas sobre a aplicação da TOC instituições públicas e identificar como a utilização dessa ferramenta tem impactado na gestão no âmbito do setor público.

Adicionalmente, este artigo contribui no preenchimento de uma lacuna encontrada na literatura quanto ao fato de que, de acordo com Souza (2005), ainda que não mais se possa considerar a Teoria das Restrições (TOC) como uma abordagem efetivamente nova de se gerenciar organizações, o volume de falsos entendimentos acerca do assunto é muito grande, o que torna essencial entender este conceito com a devida profundidade essencial para uma efetiva compreensão dos potenciais benefícios que por eles podem ser proporcionados.

E, além disso, a literatura clássica TOC discutiu completamente o objetivo e medidas de desempenho para o setor privado, mas a literatura equivalente para o setor público é escassa e não cobrem todas as medidas de desempenho, existindo assim uma lacuna na literatura, para se construir uma estrutura conceitual para implementação da TOC no setor público (SADAT; CARTER; GOLDEN, 2013). Essa lacuna é ainda reforçada por Ikeziri et al. (2018) que conclui que existem muitos pesquisadores trabalhando em todo o mundo para aprimorar os conceitos de TOC e explorar as possibilidades para a sua aplicação, entretanto, poucos estudos tentaram sistematizar conhecimento existente sobre o assunto.

Essas colocações vão de encontro com as conclusões apresentadas anteriormente, por Andrade (2012) e Cavalcante et. al (2017), quanto à intensa transformação que o serviço público brasileiro vem sofrendo na busca por uma prestação de serviço mais eficiente. Dessa feita, pode-se afirmar que tudo isso confirma o quanto toda essa discussão vem somar esforços para a melhoria de ações no setor público.

Cabe ressaltar, que este trabalho pretende contribuir, do ponto de vista teórico, para a literatura relacionada às práticas de gestão no setor público, ao resgatar os trabalhos que abordaram uma metodologia voltada para as especificidades da realidade do setor. Identificando assim, os pontos críticos da aplicação TOC no setor público, bem como oportunidades de pesquisas futuras. Do ponto de 
vista prático, a apresentação de uma síntese dos resultados, até então alcançados, servirá de subsídio aos agentes públicos e pesquisadores para pesquisas e desenvolvimento de trabalhos futuros em suas instituições. Por fim, julga-se que a contribuição com o conhecimento científico se refere à compreensão sobre como a TOC tem sido utilizada como mecanismo de melhoramento contínuo para os processos e estratégias dos órgãos públicos.

O presente artigo encontra-se estruturado em cinco seções. A primeira seção contextualizou o tema de pesquisa que será investigado neste estudo. A seção dois apresenta um breve referencial teórico sobre os principais temas. Na terceira seção são mostrados os procedimentos metodológicos. Na quarta seção são exibidos os resultados do artigo. Por fim, a quinta seção concluiu o estudo, seguida das referências bibliográficas.

\section{Fundamentação teórica}

\subsection{A Teoria das Restrições}

Segundo Lacerda, Rodrigues e Neto (2007), o termo restrição é definido como todo e qualquer fator que limita e empresa à consecução da sua meta. De acordo com Lacerda e Rodrigues (2011), inicialmente a meta proposta era: "ganhar dinheiro hoje e no futuro". Todavia, posteriormente essa visão foi ampliada adicionando-se os seguintes aspectos: "satisfazer os empregados hoje e no futuro" e "satisfazer os clientes hoje e no futuro".

A Teoria das Restrições, cujo termo em inglês é dado por Theory of Constraints (TOC) é uma metodologia de pensamento estratégico e gerenciamento criada nos anos 80 por um físico alemão, Eliahu M. Goldratt, desenvolvida com o objetivo de dispensar esforços naquilo que é restrição de capacidade ou gargalo da produção (Slack, Chambers, \& Johnston, 2009).

De acordo com Marques \& Cia (1998), a TOC foi inicialmente introduzida por meio da publicação do livro The goal, em 1985, de autoria do Goldtratt, escrito sob a forma de romance. Neste livro são descritas as experiências do autor na implementação de métodos de otimização de processos industriais, em especial pelo emprego do programa Optimum Production Technology (OPT), uma aplicação metodológica de Pesquisa Operacional.

A abordagem do programa OPT recomenda que as restrições sejam gerenciadas de acordo com o seguinte processo decisório: (1) identificação dos fatores que restringem o processo; (2) definição de como explorar as restrições; (3) subordinação de todos os aspectos às decisões tomadas acima; (4) elevação das restrições e, (5) retomo ao elo agora mais fraco, sem deixar que a inércia se tome a nova restrição (Goldratt \& Cox, 2002). 
Ainda para Goldratt \& Cox (2002), o ápice da TOC está no fato de se focar nas restrições, ou seja, buscar um reforço para os elos fracos na produtividade, na entrega e demais funções, a fim de aumentar o lucro e ter um melhor fluxo de trabalho.

Além do mais, a TOC estabelece a restrição como causa da maioria dos problemas empresariais e aponta que o melhor gerenciamento dos recursos existentes, com foco em encontrar o elo mais fraco do processo, ou seja, o gargalo produtivo, é o que pode vir a maximizar a melhoria no nível de serviço. O gargalo produtivo é definido como o setor ou pessoa que recebe uma carga maior do que é capaz de produzir (Pacheco, Luz, Rocha, Dornelles, \& Antunes, 2012).

Um ponto importante destacado por Ikeziri, Fiorini, \& Souza (2016), é que a implementação da TOC melhora os resultados que por sua vez impactam positivamente na performance organizacional. Seu foco excede os limites dos gargalos de fábrica, planejamento de produção, controle e agendamento de técnicas para se tornar uma filosofia de gestão global focada em alavancar o desempenho e oferecer vantagens competitivas decisivas às organizações.

Segundo Lima e Souza (2018), a TOC é composta dos seguintes itens: métrica das restrições e processo das restrições. A métrica da teoria das restrições é uma de suas variáveis principais e consiste na resposta à três questões básicas para a tomada de decisão: "Qual o impacto no ganho da empresa?", "Qual o impacto no inventário?", e, por fim, "Qual o impacto na despesa operacional?".

Ainda para Lima e Souza (2018), o processo das restrições constitui-se de um ciclo, envolvendo cinco etapas para o gerenciamento da restrição a saber: identificar a restrição no sistema, explorar a restrição, subordinar todos os recursos do sistema à restrição, elevar a capacidade da restrição e procurar por outras restrições, evitando que a inercia se torne uma restrição (Quadro 1).

\section{Quadro 1}

Etapas da Teoria das Restrições

\section{Etapa}

Identificar a restrição do sistema

Elevar o nível da restrição

Subordinar todo o sistema à exploração da restrição

Aumentar a produção da restrição

Começar todos os passos novamente

Fonte: Adaptado de Lima e Souza (2018).

\section{Descrição}

Mapeamento do fluxo de valor: ferramenta para descobrir as restrições dos processos de trabalho ou observação empírica de estoque em processo Encontrar uma forma de explorar a restrição: conseguir atingir uma melhora no seu rendimento, aumentando a produtividade

Os demais recursos devem trabalhar no ritmo da restrição

Aquisição de uma nova máquina; terceirização do processo de trabalho ou envio para outras fábricas aquilo que passaria pela restrição

Renovar o ciclo de melhoria para elevar a inércia do sistema 
Por fim, Souza, Schmitt, Pinto, \& Favero (2016) mencionam que a implementação da TOC possibilita uma visão mais ampla do processo, permitindo assim a identificação e aperfeiçoamento das interfaces funcionais, que são os pontos nos quais o trabalho que está sendo realizado e transferido de um setor para o seguinte. Percebe-se que o método se constitui de uma ferramenta importante para identificar as competências necessárias para cada função (Souza et al. 2016), sendo dessa forma, uma ferramenta interessante que pode ser aplicada para a melhoria da eficiência dos processos institucionais de qualquer organização pública.

\section{2 o Serviço Público e suas características}

O serviço público brasileiro é regulado por leis específicas e pela Constituição do Brasil (1988) que determina, no caput do artigo 37, a obediência aos princípios de legalidade, impessoalidade, moralidade, publicidade e eficiência e ainda os mecanismos de controle interno e externo (Constituição do Brasil, 1988).

Segundo Santos (2018), no decorrer do processo de evolução do Estado, a teoria burocrática perdeu a sua função inicial que era a de orientar e organizar o trabalho administrativo, baseada na racionalidade, dando origem ao que se chama de disfunção burocrática, que corresponde às anomalias e imperfeições no seu funcionamento, como a falta de eficiência da organização, desperdícios dos recursos de materiais, rotina e apego dos funcionários a seus cargos e funções, bem como lentidão na resolução dos problemas.

Além da disfunção burocrática, Fernandes (2018) menciona que as instituições públicas ainda enfrentam os problemas advindos de frequentes cortes de orçamento, estruturas rígidas, dentre outros, característicos do meio público e que atravancam o fluxo de suas atividades, impedindo-as de cumprir eficientemente sua missão.

Considerando esses problemas, para Bravo e Mariano (2006), faz-se necessário o desenvolvimento de procedimentos e instrumentos eficazes para auxiliar na tomada de decisão .

Quando se olha para este cenário, são percebidos esforços nas organizações públicas no sentido de modernização administrativa, como por exemplo a criação do Programa Nacional de Gestão Pública e Desburocratização (GesPública), criado em 2005, com o objetivo de aumentar a competitividade das organizações públicas e contribuir para a melhoria da qualidade de vida do cidadão, instrumentalizando uma gestão pública por resultados e assegurando a obtenção de lucros sociais decorrentes de bons produtos e serviços (GesPública, 2005).

Para o cerne da administração pública, considerada todas as suas peculiaridades, Luchi (2006) já prescrevera que sob a ótica da Teoria das Restrições, a eficácia do desempenho global de uma 
organização deixa de ser compreendida como o resultado da soma de recursos eficientes e passa a ser entendida como uma eficiente interação dos recursos disponíveis.

Logo, as ferramentas da TOC têm potencial para otimizar qualquer processo que as organizações públicas venham a desenvolver, de forma a prover um diagnóstico, a partir de uma visão sistêmica, onde se analisa o resultado da interação desses gargalos entre si, a fim de descobrir aquele que mais contribui para a ocorrência dos demais (Luchi, 2006).

Nesse sentido, o mapeamento e a modelagem de processos, uma das etapas estabelecidas na Teoria das Restrições, pode propiciar maior compreensão dos processos e da estrutura dos órgãos públicos, além de proporcionar uma visualização de como se dão os fluxos de trabalho entre os departamentos. Essas informações se tornam cada vez mais necessárias para compreender de forma sistêmica o funcionamento dos processos que existem nas instituições públicas, auxiliando também na identificação dos gargalos e na proposição de um conjunto de ações necessárias para melhorar a entrega de valor para a população, bem como a eficiência dos serviços públicos.

\section{Método de pesquisa}

A Revisão Sistemática de Literatura (RSL) pode ser compreendida como um processo de análise e coleta de informações bem estabelecido, de forma a mapear imparcialmente as evidências relevantes sobre determinado assunto, avaliar a qualidade dessas evidências e sintetizá-las em relatos do que é conhecido e o que não é conhecido sobre uma questão (Hansen \& Trifkovic, 2013).

A metodologia de pesquisa utilizado foi uma RSL, classificada como de caráter descritivodiscursivo, por proporcionar uma maior familiaridade com o tema pesquisado. O método escolhido para desenvolver o estudo foi seguido pelos passos propostos por Jesson, Matheson \& Lacey (2011) que consistem em: (1) busca da literatura pertinente ao tema nos bancos de dados; (2) avaliação e seleção dos artigos; (3) extração dos dados; (4) síntese e análise dos dados em tabelas; e (5) apresentação dos resultados.

O período da pesquisa foi estabelecido entre os anos de 2009 e 2019, identificando as principais discussões acadêmicas sobre o assunto. O intervalo escolhido para a pesquisa tomou por base o estudo de Dutra et al. (2019) que sinaliza para futuras pesquisas sobre a TOC levar em consideração o período mínimo de 2009 a 2013, por esse período representar cerca de 55\% da quantidade de artigos analisados em sua pesquisa, sendo, portanto, uma continuidade na análise dos dados desta temática.

Para a coleta dos dados, foram pesquisados nas bases de dados do Google Scholar $\AA$, Scopus $®$ e Web of Science ${ }^{\circledR}$. Além disso, foram estabelecidos os termos para a busca, informados entre aspas (“'”) no campo principal de busca, sendo determinada ainda com lógica booleana (AND) com o termo 
"Government" e suas variações, como strings de busca, conforme mostra o Quadro 2. A busca foi realizada pela análise do tema nos títulos, resumos e palavras-chave, a fim de filtrar resultados pretendidos.

\section{Quadro 2}

Strings de busca

\begin{tabular}{|l|l|}
\hline \multicolumn{1}{|c|}{ Termo } & \multicolumn{1}{|c|}{ Variações } \\
\hline Theory of constraints & TOC, bottlenecks \\
\hline Public administration & $\begin{array}{l}\text { Government, Public Sector, Public Organizations, Public Agencies, } \\
\text { Public Management }\end{array}$ \\
\hline
\end{tabular}

Fonte: Elaborado pelo autor.

Buscou-se incluir os trabalhos pela relevância em relação às questões de investigação, determinada pela análise preliminar do título, palavras-chave e resumo. Nesta análise buscou-se identificar os estudos que trataram primária ou secundariamente, do processo de aplicação da metodologia TOC em órgãos públicos.

Na seleção desta pesquisa, pela análise preliminar do título, palavras-chave e resumo, foram excluídas as pesquisas claramente irrelevantes para o estudo, ou aqueles que apresentem texto, conteúdo e resultados que não estejam alinhados com os objetivos desta pesquisa, não contribuindo para a questão de pesquisa que é identificar como essa ferramenta tem impactado a gestão no âmbito do setor público.

Além disso, para se atingir o objetivo estabelecido neste artigo, foram definidas algumas questões de pesquisa, que serão respondidas ao longo deste artigo. As perguntas são:

1. Quais são as áreas do setor público que têm aplicado os princípios da TOC?

2. Quais foram as perspectivas da TOC utilizadas?

3. Quais são as restrições identificadas?

4. Quais são os objetivos dos trabalhos para se utilizar a TOC?

5. Quais foram os resultados organizacionais das aplicações da TOC?

6. Quais são pontos positivos de se utilizar TOC no setor público identificados pelos trabalhos?

7. Quais são as dificuldades de se utilizar a TOC?

8. Quais foram as condições de partida dos processos avaliados?

9. Quais são as possíveis propostas de trabalhos futuros? 
4 Resultados

A seguir, são apresentados os trâmites realizados nesta revisão e as respectivas decorrências encontradas, seguindo os tópicos, as etapas da RSL propostos por Jesson, Matheson \& Lacey (2011).

\subsection{Busca da literatura pertinente ao tema nos bancos de dados}

Os primeiros filtros realizados foram limitar a pesquisa aos últimos 10 anos, e aos documentos do tipo 'artigo', 'revisão' e 'artigos aceitos para publicação'. Eles foram escolhidos para fornecer um espectro amplo e qualificado da literatura acadêmica sobre o tema.

O número total de artigos encontrados após a filtragem é mostrado na Tabela 1. Inicialmente, foram apresentadas 146 publicações, sendo 10 trabalhos na base de dados do Scopus ${ }^{\circledR}, 9$ no Web of Science $®$ e 127 no ScienceDirect ${ }^{\circledR}$.

Tabela 1

Número de artigos localizado nos bancos de dados

\begin{tabular}{l|c|c|c|c}
\multicolumn{1}{c|}{$\begin{array}{l}\text { Strings } \\
\text { "Theory of Constraints" AND "Government" }\end{array}$} & $\begin{array}{c}\text { Scopus } ® \\
\text { Science } ®\end{array}$ & $\begin{array}{c}\text { Science } \\
\text { Direct } ®\end{array}$ & Total \\
\hline "Theory of Constraints" AND "Public Administration" & 5 & 8 & 117 & 130 \\
\hline "Theory of Constraints" AND "Public Agencies" & 2 & 1 & 6 & 9 \\
\hline "Theory of Constraints" AND "Public management" & 0 & 0 & 2 & 2 \\
\hline "Theory of Constraints" AND "Public Sector" & 1 & 0 & 2 & 3 \\
\hline TOTAL GERAL & 10 & 9 & 0 & 2 \\
\hline
\end{tabular}

Fonte: Dados coletados pelo autor.

De posse da delimitação das bases e dos termos que pudessem abranger o estudo, passou-se ao passo 3, que tratou da seleção dos artigos que o levantamento inicial apresentou.

\subsection{Avaliação e seleção dos artigos}

Foi realizada uma triagem para identificar artigos duplicados entre as três bases, sendo encontrado um total de 11 ocorrências para o fato. Em seguida, os artigos resultantes da triagem foram analisados por título, resumo e palavras-chave para verificar se o trabalho encontrado de fato tinha alguma ligação com o tema pesquisado; este refinamento resultou em 20 trabalhos que compuseram a amostra final, conforme apresentado no Quadro 3. 
Quadro 3

\section{Resultado da triagem título/resumo/palavras-chave}

\begin{tabular}{|c|c|c|}
\hline Título & Autor; Ano & Objetivo do estudo \\
\hline $\begin{array}{l}\text { A framework for emergency department } \\
\text { capacity planning using system dynamics } \\
\text { approach and the theory of constraints } \\
\text { philosophies }\end{array}$ & $\begin{array}{l}\text { (Ahmad, Ghani, Kamil, \& } \\
\text { Tahar, 2010) }\end{array}$ & $\begin{array}{l}\text { Propor um híbrido de abordagem de Dinâmica } \\
\text { do Sistema e a TOC na resolução do } \\
\text { planejamento da capacidade de saúde. }\end{array}$ \\
\hline $\begin{array}{l}\text { Applying Theory of Constraints in Administrative } \\
\text { Process: An Experiment from the US Government }\end{array}$ & (Knaggs et al., 2012) & $\begin{array}{l}\text { Aplicar da TOC nos processos administrativos do } \\
\text { Governo dos Estados Unidos }\end{array}$ \\
\hline $\begin{array}{l}\text { Business Process Improvement in a } \\
\text { Governmental Shared Service Centre: A New } \\
\text { Approach to BPR }\end{array}$ & (Aydinli \& Ravesteijn, 2009) & $\begin{array}{l}\text { Descrever um projeto de melhoria de processos } \\
\text { de negócios em um centro de serviço } \\
\text { compartilhado }\end{array}$ \\
\hline $\begin{array}{l}\text { Effect Of Supplier Selection Criteria On } \\
\text { Performance Of The Procurement Function Of } \\
\text { County Governments In Kenya }\end{array}$ & (Nyakoe \& Muturi, 2017) & $\begin{array}{l}\text { Descrever dos efeitos dos critérios de seleção de } \\
\text { fornecedores no desempenho da função de } \\
\text { compras dos governos }\end{array}$ \\
\hline $\begin{array}{l}\text { Improving labour relations performance using a } \\
\text { Simplified Drum Buffer Rope technique }\end{array}$ & (Chakravorty \& Hales, 2016) & Aplicar da TOC em uma base militar dos EUA \\
\hline $\begin{array}{l}\text { Joint venture housing projects in Dar es Salaam } \\
\text { city: An analysis of challenges and effectiveness }\end{array}$ & (Kavishe \& Chileshe, 2017) & $\begin{array}{l}\text { Identificar os desafios e avaliar a eficácia dos } \\
\text { projetos NHC-JV }\end{array}$ \\
\hline $\begin{array}{l}\text { SoS Methodologies for the Definition of Lean } \\
\text { Manufacturing Systems }\end{array}$ & $\begin{array}{l}\text { (Alfieri, Cantamessa \& } \\
\text { Montagna, 2009) }\end{array}$ & $\begin{array}{l}\text { Propor uma metodologia inovadora baseado no } \\
\text { contexto de iniciativas militares complexas }\end{array}$ \\
\hline $\begin{array}{l}\text { The Problem of Capacity Management in Greek } \\
\text { Public Hospitals }\end{array}$ & $\begin{array}{l}\text { (Tsitsakis, Polychronidou, \& } \\
\text { Karasavvoglou, 2016) }\end{array}$ & $\begin{array}{l}\text { Gerenciar da capacidade nos hospitais públicos } \\
\text { gregos }\end{array}$ \\
\hline $\begin{array}{l}\text { The thinking process of the theory of constraints } \\
\text { applied to public healthcare }\end{array}$ & $\begin{array}{l}\text { (Bauer, Sellitto, Vargas, } \\
\text { Souza, \& Vaccaro, 2019) }\end{array}$ & $\begin{array}{l}\text { Aplicar o processo de pensamento da teoria das } \\
\text { restrições aplicadas à saúde pública }\end{array}$ \\
\hline $\begin{array}{l}\text { Toward a model of performance measurement } \\
\text { of output based on the Theory of Constraints }\end{array}$ & (Hirtz \& Guernaccini, 2015) & $\begin{array}{l}\text { Introduzir uma primeira reflexão sobre um } \\
\text { modelo de medição de desempenho baseado na } \\
\text { TOC. }\end{array}$ \\
\hline $\begin{array}{l}\text { Using the Theory of Constraints to resolve long- } \\
\text { standing resource and service issues in a large } \\
\text { public hospital }\end{array}$ & $\begin{array}{l}\text { (Mabin, Yee, Babington, } \\
\text { Caldwell, \& Moore, 2017) }\end{array}$ & $\begin{array}{l}\text { Aplicar TOC para resolver questões de recursos e } \\
\text { serviços em um grande hospital público }\end{array}$ \\
\hline $\begin{array}{l}\text { Applying the TOC five-step focusing process in } \\
\text { surgical process }\end{array}$ & $\begin{array}{l}\text { (Ren, Luo, Yang, Ji, \& Gong, } \\
\text { 2013) }\end{array}$ & $\begin{array}{l}\text { Aplicar o processo de focalização de cinco } \\
\text { etapas do TOC no processo cirúrgico }\end{array}$ \\
\hline $\begin{array}{l}\text { Applying theory of constraints to the Indian } \\
\text { Administrative Services }\end{array}$ & (Mishra \& Sasmita, 2014) & $\begin{array}{l}\text { Aplicar teoria das restrições aos serviços } \\
\text { administrativos indianos }\end{array}$ \\
\hline $\begin{array}{l}\text { Developments in public sector financial } \\
\text { management in Estonia }\end{array}$ & (Tikk \& Almann, 2011) & $\begin{array}{l}\text { Aplicar a TOC para o desenvolvimento na gestão } \\
\text { financeira do setor público na Estônia }\end{array}$ \\
\hline $\begin{array}{l}\text { Exploring the bottleneck of Iran's national } \\
\text { innovation system by TOC thinking process }\end{array}$ & $\begin{array}{l}\text { (Abdi, Hasanzadeh, \& Fani, } \\
\text { 2014) }\end{array}$ & $\begin{array}{l}\text { Explorar o gargalo do sistema nacional de } \\
\text { inovação do Irã }\end{array}$ \\
\hline $\begin{array}{l}\text { Improving decision-making and management of } \\
\text { hospital resources: An application of the } \\
\text { PROMETHEE II method in an Emergency } \\
\text { Department Operations }\end{array}$ & (Amaral \& Costa, 2014) & $\begin{array}{l}\text { Descrever a aplicação do método PROMETHEE II } \\
\text { para apoiar a tomada de decisões e o } \\
\text { gerenciamento de recursos. }\end{array}$ \\
\hline $\begin{array}{l}\text { Improving intergovernmental information } \\
\text { processes: in search of the appropriate } \\
\text { management strategy }\end{array}$ & $\begin{array}{l}\text { (Cauter, Crompvoets, \& } \\
\text { Voets, J., 2012) }\end{array}$ & $\begin{array}{l}\text { Identificar a melhoria dos processos de } \\
\text { informação intergovernamental }\end{array}$ \\
\hline $\begin{array}{l}\text { Institutional and regulatory constraints in } \\
\text { managing procurement records: Exploratory } \\
\text { case of procuring entities in Tanzania }\end{array}$ & (Rasheli \& Mwagike, 2018) & $\begin{array}{l}\text { Identificar e avaliar as restrições regulatórias e } \\
\text { institucionais na gestão de registros de } \\
\text { aquisições em entidades compradoras da } \\
\text { Tanzânia }\end{array}$ \\
\hline $\begin{array}{l}\text { Integrating public and business management: a } \\
\text { model of interaction between public and private } \\
\text { sectors }\end{array}$ & (Gudelis \& Guogis, 2011) & $\begin{array}{l}\text { Aplicar a TOC para a integração gestão pública e } \\
\text { empresarial }\end{array}$ \\
\hline $\begin{array}{l}\text { Internal Factors Affecting Efficiency Of Public } \\
\text { Procurement Process In County Governments In } \\
\text { Kenya: A Case Of Kisumu County }\end{array}$ & (Ochieng, 2018) & $\begin{array}{l}\text { Identificar os fatores internos que afetam a } \\
\text { eficiência do processo de licitação no município } \\
\text { do Quênia }\end{array}$ \\
\hline
\end{tabular}

Fonte: Elaborado pelos autores. 
Com os dados levantados, foi possível fazer a análise sobre as pesquisas direcionadas à aplicação da TOC nos processos administrativos do setor público, e apresentar as áreas do setor público que têm aplicado os princípios de TOC, os objetivos dos trabalhos para se utilizar a ferramenta, as perspectivas utilizadas, as restrições identificadas, os resultados, pontos positivos e dificuldades de se utilizar a TOC, além de possíveis propostas de trabalhos futuros, respondendo assim a todos as questões de pesquisa estabelecidas ao início do estudo.

Conforme mostra o Gráfico 1, as áreas com maior concentração de estudos sobre a implementação da TOC foram as de saúde e compras e contratações, correspondendo a 50\% do total acumulado dos estudos pré-selecionados.

\section{Gráfico 1}

Áreas Objeto de estudo

Fonte: Elaborado pelos autores.

No que tange aos números de trabalhos publicados por ano no intervalo selecionado, a pesquisa mostra uma pequena variância entre 1 e 3 artigos por ano, sendo os anos de 2011, 2014 e 2017 os que concentraram o maior número.

Após esta etapa, os resultados e conclusões foram tratados pela Técnica de Análise de Conteúdo. Esta técnica, segundo Bardin (2006), precisa seguir três fases: a análise prévia, análise de conteúdo e interpretação do resultado.

\subsection{Extração dos dados}

$\mathrm{Na}$ fase de análise prévia, etapa em que foi realizada uma leitura flutuante nos artigos com o objetivo de organizar o material encontrado e separar aqueles que fariam parte da análise final, foi realizada a triagem primária dos artigos, organizando-os considerada a sua relevância em relação ao tema (Bardin, 2016).

Segundo Bardin (2006), a leitura flutuante é o contato mais aprofundado com os documentos a serem analisados, em que se conhece o contexto e se extrai os aspectos importantes para as próximas fases da análise.

A escala utilizada nesta triagem, baseou-se na metodologia aplicada por Wasserbaur e Sakao (2018), a saber: 
1. Baixa relevância: Não é claro o uso do conceito e/ou técnicas da TOC ou uma descrição vaga dos impactos obtidos com o uso da teoria no setor público estudado.

2. Relevância média: É claro o uso do conceito e/ou técnicas da TOC no setor estudado, contudo, não resta claro quanto aos impactos obtidos.

3. Alta relevância: O uso do conceito e/ou técnicas da TOC são abordadas e as interligações são descritas.

Nesta fase, detectou-se que em dez artigos não fica claro o uso do conceito e/ou técnicas da TOC, em dois artigos não houve uma descrição dos impactos obtidos com o uso da teoria e um não tratava da aplicação da teoria em setor público; oito artigos foram considerados de alta relevância e quatro enquadram-se como de média relevância. Ao final da triagem o resultado apresentado é demonstrado no Quadro 4.

\section{Quadro 4}

\section{Amostra final para análise}

\begin{tabular}{|c|c|c|}
\hline Autores & Relevância & Tema central \\
\hline (Abdi et.al, 2014) & Alta & Identificar problemas utilizando o TOC-TP e para eliminar os gargalos \\
\hline (Aydinli \& Ravesteijn, 2009) & Alta & $\begin{array}{l}\text { Melhoria de processos de negócios em um centro de serviços } \\
\text { compartilhados }\end{array}$ \\
\hline (Bauer et al., 2019) & Alta & $\begin{array}{l}\text { Abordagem do TP para diagnosticar e melhorar os sistemas de saúde } \\
\text { pública }\end{array}$ \\
\hline (Chakravorty \& Hales, 2016) & Alta & $\begin{array}{l}\text { Descrever a implementação do S-DBR em operações de serviço de base } \\
\text { militar }\end{array}$ \\
\hline (Hirtz \& Guernaccini, 2015) & Média & Medir o desempenho do processo operacional de reengenharia \\
\hline (Knaggs et al. 2012) & Alta & Avaliar a implementação da TOC na divisão de aquisições \\
\hline (Mabin et al, 2017) & Alta & $\begin{array}{l}\text { TOC na rotina de um hospital público para representação lógica das } \\
\text { restrições }\end{array}$ \\
\hline (Mishra \& Sasmita, 2014) & Média & Identificar as limitações enfrentadas pelos oficiais do serviço policial \\
\hline (Rasheli \& Mwagike, 2018) & Média & Identificar e avaliar as restrições no controle patrimonial \\
\hline (Tsitsakis et.al 2016) & Alta & $\begin{array}{l}\text { Avaliar o problema do gerenciamento da capacidade nos hospitais } \\
\text { públicos }\end{array}$ \\
\hline
\end{tabular}

Fonte: ElaboraAtoFiguturgaltompsesenta os setores e países de origem dos trabalhos selecionados. Nota-se o destaque de contribuição dos Estados Unidos, com 3 publicações em áreas distintas.

Figura 1

Origem dos estudos selecionados

Fonte: Elaborado pelos autores. 
Nesta fase, foram analisados os artigos de média e alta relevância, extraindo-se destes as interações identificadas com o tema; foi realizada uma análise dos resultados e conclusões obtidos nos trabalhos selecionados. O Quadro 5 apresenta a síntese dos conteúdos observados nos artigos selecionados na fase 2 da triagem:

\section{Quadro 5}

\section{Conteúdos}

\begin{tabular}{|c|c|c|c|}
\hline Referência & Objeto de Estudo & Procedimentos & Conclusões \\
\hline $\begin{array}{l}\text { (Knaggs et } \\
\text { al., 2012) }\end{array}$ & $\begin{array}{l}\text { Avaliar a } \\
\text { implementação da TOC } \\
\text { na divisão de } \\
\text { aquisições do Governo } \\
\text { dos EUA (Compras, } \\
\text { Planejamento e } \\
\text { Controle). } \\
\text { (Governo dos EUA) }\end{array}$ & $\begin{array}{l}\text { - Período de experimentação de } \\
\text { dois anos em treze divisões de } \\
\text { aquisições. } \\
\text { - O experimento prosseguiu em } \\
\text { três etapas sequenciais: } \\
\text { 1) estudo piloto; } \\
\text { 2) introdução da metodologia } \\
\text { TOC / DBR em uma divisão } \\
\text { experimental; } \\
\text { 3) otimizar a produção de } \\
\text { aquisições no novo Fluxo de TOC. }\end{array}$ & $\begin{array}{l}\text { - A TOC, e sua variante Drum-Buffer-Rope } \\
\text { (DBR), foram implementadas com sucesso } \\
\text { no complexo processo administrativo de } \\
\text { compras. } \\
\text { - O plano sequencial original nem sempre foi } \\
\text { seguido e alterações paralelas foram criadas } \\
\text { devido ao desejo da gerência de tomar } \\
\text { vantagem do sucesso no TOC antes do } \\
\text { planejado. } \\
\text { - Uma cultura de disciplina de TOC ainda está } \\
\text { sendo aprendida. }\end{array}$ \\
\hline $\begin{array}{l}\text { (Aydinli \& } \\
\text { Ravesteijn, } \\
\text { 2009) }\end{array}$ & $\begin{array}{l}\text { Melhoria de processos } \\
\text { de negócios em um } \\
\text { centro de serviços } \\
\text { compartilhados do } \\
\text { governo } \\
\text { (concentrando-se as } \\
\text { áreas de TI, } \\
\text { Suprimentos, Pessoal e } \\
\text { Financeiro) } \\
\text { (Governo da Holanda) }\end{array}$ & $\begin{array}{l}\text { - A pesquisa utilizou o método de } \\
\text { reengenharia de processos de } \\
\text { negócios (BPR) desenvolvido pela } \\
\text { Universidade de Utrecht, } \\
\text { seguindo as seguintes etapas: } \\
\text { 1) Mapeamento da arquitetura de } \\
\text { informações corporativas do } \\
\text { departamento. } \\
\text { 2) Escolha da estratégia. } \\
\text { 3) Definição dos processos } \\
\text { principais usando a modelagem }\end{array}$ & $\begin{array}{l}\text { Depois de usar o método BPR para um } \\
\text { projeto de melhoria, os resultados foram } \\
\text { claramente positivos. A TOC foi usada para } \\
\text { melhorar a capacidade de prestação de } \\
\text { serviços e simplificar seus processos; com } \\
\text { isso o montante de contas a pagar foi } \\
\text { reduzido, enquanto o processo de aquisição } \\
\text { passou a ser executado com menos recursos } \\
\text { que antes. Espera-se que a eficiência dos } \\
\text { processos de negócios e a qualidade da } \\
\text { prestação de serviços possam ser } \\
\text { melhorados com a implementacão de várias }\end{array}$ \\
\hline
\end{tabular}




\begin{tabular}{|c|c|c|c|}
\hline Referência & Objeto de Estudo & Procedimentos & Conclusões \\
\hline & & $\begin{array}{l}\text { de processos de negócios } \\
\text { alinhada com a estratégia. } \\
\text { 4) Otimização dos processos. } \\
\text { 5) Escolha da estratégia de gestão } \\
\text { do conhecimento alinhada com a } \\
\text { estratégia. } \\
\text { 6)Definir, e implementar, } \\
\text { mecanismos de controle para } \\
\text { todos os departamentos } \\
\text { envolvidos. }\end{array}$ & $\begin{array}{l}\text { outras recomendações que foram } \\
\text { encontradas durante o projeto. No entanto, } \\
\text { mais tempo e investimentos financeiros } \\
\text { serão necessários. }\end{array}$ \\
\hline $\begin{array}{l}\text { (Hirtz \& } \\
\text { Guernaccini, } \\
\text { 2015) }\end{array}$ & $\begin{array}{l}\text { O objetivo do projeto é } \\
\text { medir o desempenho } \\
\text { do processo } \\
\text { operacional em uma } \\
\text { administração pública } \\
\text { no âmbito de um } \\
\text { processo de } \\
\text { reengenharia }\end{array}$ & $\begin{array}{l}\text { - Construir os indicadores de } \\
\text { desempenho da saída / resultado, } \\
\text { com a abordagem comum do } \\
\text { "desempenho global". } \\
\text { - Definir meta. } \\
\text { - Estágio de teste de dois meses. }\end{array}$ & $\begin{array}{l}\text { Mostra a contribuição mútua do TOC e do } \\
\text { conceito de saída. Por um lado, a } \\
\text { operacionalização do conceito de saída é } \\
\text { mais fácil; por outro lado, facilita a } \\
\text { adaptação do TOC no setor público. Este } \\
\text { sistema facilita o processo de tomada de } \\
\text { decisão para ambos, a gerência e o pessoal } \\
\text { operacional. }\end{array}$ \\
\hline $\begin{array}{l}\text { (Chakravorty } \\
\text { \& Hales, } \\
2016 \text { ) }\end{array}$ & $\begin{array}{l}\text { O objetivo desta } \\
\text { pesquisa é descrever } \\
\text { uma implementação de } \\
\text { (S-DBR), em operações } \\
\text { de serviço de uma base } \\
\text { militar dos EUA. }\end{array}$ & $\begin{array}{l}\text { O estudo de caso descreve a } \\
\text { implementação de seis meses de } \\
\text { S-DBR para melhorar a relação de } \\
\text { desempenho em um contexto de } \\
\text { serviço. A implementação foi } \\
\text { realizada em quatro fases } \\
\text { distintas: } 1 \text { ) treinamento dos } \\
\text { especialistas; } 2 \text { ) análise do fluxo } \\
\text { de trabalho e desenvolvimento de } \\
\text { nova configuração celular; } 3 \text { ) } \\
\text { realocação física dos escritórios } \\
\text { para o novo fluxo de trabalho; } 4) \\
\text { implementação do S-DBR para } \\
\text { controlar fluxo para as células. }\end{array}$ & $\begin{array}{l}\text { A utilização das premissas do S-DBR, levou a } \\
\text { um melhor desempenho porque ao } \\
\text { contrário de Lean, Six Sigma e outros } \\
\text { métodos que evitar gargalos internos, o S- } \\
\text { DBR gerenciou a demanda colocada no } \\
\text { sistema. }\end{array}$ \\
\hline $\begin{array}{l}\text { (Tsitsakis et } \\
\text { al., 2016) }\end{array}$ & $\begin{array}{l}\text { O estudo avalia o } \\
\text { problema do } \\
\text { gerenciamento da } \\
\text { capacidade nos } \\
\text { hospitais públicos } \\
\text { gregos } \\
\text { (Grécia) }\end{array}$ & $\begin{array}{l}\text { O estudo baseou-se nas } 5 \text { etapas } \\
\text { da TOC, por meio de uma } \\
\text { pesquisa qualitativa exploratória, } \\
\text { através de entrevistas com } \\
\text { médicos e diretores clínicos de } \\
\text { clínicas específicas, de forma a } \\
\text { fornecer insights sobre o } \\
\text { problema e ajudar a desenvolver } \\
\text { ideias ou hipóteses para pesquisa } \\
\text { quantitativa potencial. }\end{array}$ & $\begin{array}{l}\text { A TOC pode ser aplicada com sucesso para } \\
\text { resolver os problemas de gerenciamento de } \\
\text { capacidade das organizações de saúde, } \\
\text { reduzindo o tempo de internação de } \\
\text { internação e aumentar a satisfação dos } \\
\text { serviços oferecidos. }\end{array}$ \\
\hline $\begin{array}{l}\text { (Bauer et al., } \\
\text { 2019) }\end{array}$ & $\begin{array}{l}\text { O objetivo é apresentar } \\
\text { uma abordagem } \\
\text { baseada no TP-TOC } \\
\text { para apoiar } \\
\text { diagnosticar e melhorar } \\
\text { os sistemas de saúde. }\end{array}$ & $\begin{array}{l}\text { O método de pesquisa foi o } \\
\text { estudo de caso exploratório como } \\
\text { foco na busca por evidências de } \\
\text { campo sobre maneiras de } \\
\text { melhorar a qualidade do serviço } \\
\text { de um hospital filantrópico } \\
\text { através do TP-TOC. }\end{array}$ & $\begin{array}{l}\text { A implementação do TP-TOC foi relevante } \\
\text { por permitir atenção às opiniões dos } \\
\text { envolvidos, revelando, de maneira } \\
\text { construtiva, a situação atual e os problemas } \\
\text { de raiz associados à insatisfação dos } \\
\text { pacientes. }\end{array}$ \\
\hline $\begin{array}{l}\text { (Mabin et al., } \\
\text { 2017) }\end{array}$ & $\begin{array}{l}\text { O estudo analisa a } \\
\text { rotina de um hospital } \\
\text { público, usando o } \\
\text { conjunto de } \\
\text { ferramentas da (TOC) } \\
\text { para representar } \\
\text { logicamente uma }\end{array}$ & $\begin{array}{l}\text { Utilizou-se o Processo de } \\
\text { Pensamento (TP) como um dos } \\
\text { itens da metodologia da pesquisa } \\
\text { abordando as três grandes } \\
\text { questões; (1) O que mudar (2); } \\
\text { para quê mudar; (3) como causar } \\
\text { a mudança. }\end{array}$ & $\begin{array}{l}\text { A implementação do TP-TOC alcançou } \\
\text { sucesso durante um período sustentado, } \\
\text { desenvolvendo uma solução de ganha- } \\
\text { ganha-ganha que melhorava o atendimento } \\
\text { a custos reduzidos. }\end{array}$ \\
\hline
\end{tabular}




\begin{tabular}{|c|c|c|c|}
\hline Referência & Objeto de Estudo & Procedimentos & Conclusões \\
\hline & $\begin{array}{l}\text { situação problemática } \\
\text { e investigar opções } \\
\text { para resolução. }\end{array}$ & & \\
\hline $\begin{array}{l}\text { (Mishra \& } \\
\text { Sasmita, } \\
\text { 2014) }\end{array}$ & $\begin{array}{l}\text { Este artigo tenta } \\
\text { identificar as limitações } \\
\text { enfrentadas pelos } \\
\text { oficiais administrativos } \\
\text { indianos usando a TOC }\end{array}$ & $\begin{array}{l}\text { O projeto de pesquisa } \\
\text { exploratória é usado para o } \\
\text { estudo atual para procurar } \\
\text { padrões de restrições e estilos de } \\
\text { gestão de oficiais administrativos } \\
\text { indianos usando o paradigma } \\
\text { qualitativo. }\end{array}$ & $\begin{array}{l}\text { Falta de treinamento adequado e } \\
\text { insensibilidade dos agentes em relação às } \\
\text { realidades terrestres do público são } \\
\text { identificados como alguns dos pontos de } \\
\text { restrições. }\end{array}$ \\
\hline $\begin{array}{l}\text { (Abdi et.al, } \\
\text { 2014) }\end{array}$ & $\begin{array}{l}\text { Este trabalho contribui } \\
\text { para identificar } \\
\text { problemas no setor de } \\
\text { inovação do Irã } \\
\text { utilizando o TOC-TP e } \\
\text { para eliminar os } \\
\text { gargalos }\end{array}$ & $\begin{array}{l}\text { O estudo foi realizado em } 3 \\
\text { etapas: } 1 \text { ) identificar os } \\
\text { problemas raiz; } 2 \text { ) desenhar a } \\
\text { Árvore da Realidade Atual; } 3 \text { ) } \\
\text { reconhecer o gargalo do sistema. }\end{array}$ & $\begin{array}{l}\text { Com base nos achados desta pesquisa, o } \\
\text { principal gargalo encontrado é a pequena } \\
\text { participação do setor privado. }\end{array}$ \\
\hline $\begin{array}{l}\text { (Rasheli \& } \\
\text { Mwagike, } \\
\text { 2018) }\end{array}$ & $\begin{array}{l}\text { Identificar e avaliar as } \\
\text { restrições no controle } \\
\text { patrimonial (Tanzânia) }\end{array}$ & $\begin{array}{l}\text { As restrições identificadas foram } \\
\text { usadas como categorias temáticas } \\
\text { para a discussão no estudo. }\end{array}$ & $\begin{array}{l}\text { Os resultados indicam que o gerenciamento } \\
\text { e o atendimento de registros de aquisições } \\
\text { são altamente influenciados pelos fatores } \\
\text { restritivos que impedem a manutenção } \\
\text { eficiente de registros na maioria dos casos } \\
\text { estudados. }\end{array}$ \\
\hline
\end{tabular}

Fonte: Elaborado pelos autores.

É interessante notar que em grande parte dos artigos selecionados, consideraram a TOC para a identificação das restrições existentes na gestão do sistema estudado, no entanto, não consideraram as restrições existentes no cumprimento dos objetivos institucionais.

A pesquisa revelou ainda que no setor público, a metodologia tem sido aplicada em setores diversos da administração pública, com predominância na área da saúde; 3 dos 10 estudos selecionados tiveram o objeto de estudo relacionados à área da saúde pública e, o método da TOC mais utilizado é o Processo de Raciocínio, possivelmente por ser o método voltado diretamente para a eliminação dos efeitos indesejáveis observados.

Quanto aos impactos obtidos com a aplicação da TOC nos ambientes do setor público, a pesquisa aponta que a TOC sugere métodos aplicados a várias áreas como produção, projetos e distribuição e também apresenta o desenvolvimento do planejamento de métodos de controle, execução e métricas de apoio a decisão.

\subsection{Apresentação dos resultados}

Knaggs et al. (2012) implementaram a metodologia, no período de dois anos (2008-2010) em treze divisões diferentes. Ao final do estudo, os autores concluíram que no setor de aquisições houve uma média de $46 \%$ melhoria nas taxas de homologação dos contratos, enquanto nas três divisões de controle e planejamento, a melhora foi de apenas 8\%. Para os autores, isso se deve ao fato de que a 
capacidade de ver como um produto é transformado na cadeia de suprimentos, é um elemento chave do sucesso do TOC (Knaggs et al., 2012).

Além disso, a TOC, e sua variante Drum, Buffer and Rope (DBR), foram implementados com sucesso, principalmente nos processos administrativos de compras governamentais e, inicialmente a implementação teve significativa atenção da gerência, que pode não ser sustentável a longo prazo. Os problemas que limitaram o sucesso nas demais divisões foram associados à resistência cultural e balanceamento de carga de trabalho (Knaggs et al., 2012).

Segundo Mabin et.al (2017), as principais lições aprendidas com a aplicação da TOC foram o valor existente na análise de um sistema que mantém o status quo por muito tempo. Além disso, a análise permite identificar o conflito central e buscar as possibilidades de tratamento, fase de grande valor, visto que se tais tensões não resolvidas forem deixadas de lado, a produtividade é dificultada.

Ainda segundo os mesmos autores, para o sistema funcionar bem, o problema precisa ser resolvido em forma ganha-ganha, evitando compromisso e flip-flopping e a importância da colaboração não pode ser enfatizada de forma notável, pois como as situações mudam, é importante que a eficácia da política continue a ser monitorada, para garantir que os benefícios sejam sustentados.

Outro ponto importante observado na análise é que no ambiente do serviço público, existem regras que permitem e regras que bloqueiam, contudo, faz-se necessário encontrar um caminho e sugerir uma melhoria. Alguns oficiais exploram as restrições procurando brechas nas regras. O governo atualmente é receptivo a experimentos e um pouco de desvio de política é permitido se atingir o bem público; então, a melhor maneira disponível é explorar a restrição, para ver quais opções estão disponíveis (Mishra \& Sasmita, 2014).

Abdi et al. (2014) recomendam também proceder a seleção cuidadosa de parceiros potenciais, monitoramento e avaliação de projetos. Os gargalos do sistema podem ser identificados e os recursos limitados do país podem ser usados apenas para aumentar a capacidade do gargalo, de modo que a saída do sistema de inovação possa aumentar com mais rapidez e menor custo.

A pesquisa aqui realizada revelou que a complexidade do sistema público está no fato de que este é um sistema que interage constantemente com uma diversidade de situações, ambientes e influências externas que, por sua vez, interagem com questões estruturais e processuais internas que propiciam as restrições. Segundo Mishra e Sasmita (2014), qualquer que seja o padrão de interação entre os fatores externos e internos, a restrição se manifesta em uma das três arenas de assuntos estruturais, produtividade de recursos ou política desalinhada.

Adicionalmente, as restrições estruturais se manifestam nas estruturas de relatórios, nos processos seguidos dentro da organização, no fluxo de informações e no comando; restrições políticas são manifestadas na inação, confusão ou ações erradas causadas por causa da ampla direção ou posição que a liderança da organização assume em questões externas e internas; e restrições de recursos que 
se manifestam na inadequação ou falta de produtividade dos recursos físicos e humanos disponíveis no sistema.

Para mais, inúmeras ações meramente burocráticas e trabalho repetitivo muitas vezes fazem parte do dia-a-dia da administração pública, e isto pode gerar falhas pelo meio do caminho, em função da falta de controle. Uma possibilidade de minimizar essas falhas estaria na sistematização da sequência de ações, a fim de que cada responsável realize a etapa no tempo correto e de acordo com a solicitação, facilitando a identificação de possíveis melhorias e para resultados mais satisfatórios.

Esta revisão mostrou que, em grande parte dos órgãos públicos há um sistema complexo de inter-relações formais e informais, fazendo com que as prioridades sejam constantemente deslocadas, com pedidos "off-line" para adicionar novas demanda desejadas; tal circunstância acaba por exigir grande esforço em resistir às rupturas manuais que interferem diretamente na produção e rendimento, além de não propiciar medidas adequados para ajudar o gerenciamento a entender o fluxo de trabalho. A exemplo disso, Aydinli e Ravesteijn (2009) apontaram ainda dificuldade em estabelecer um processo uniforme porque em locais diferentes da unidade estudada, as tarefas eram realizadas de maneiras ligeiramente diferentes.

Poucos resultados foram relatados usando TOC para processos em que o fluxo de carga de trabalho é quase estritamente eletrônico. Possivelmente isso ocorra pelo fato de que processo eletrônicos, por sua natureza, tenham o desenho dos fluxos do processo bem definidos e, processos com devidamente definidos são mais facilmente compreendidos, portanto, as restrições serão identificadas mais claramente.

Por todo exposto, considerando as questões estabelecidas, a pesquisa atendeu os objetivos deste trabalho mostrando que:

1. As áreas do setor público que mais têm aplicado os princípios de TOC são aquelas que envolvem serviços à saúde e compras e contratações;

2. As perspectivas de maior destaque estão na identificação de problemas e auxílio no planejamento de ações futuras;

3. As restrições identificadas foram a cultura organizacional, a falta de treinamento adequado e a insensibilidade por parte de alguns agentes, além da complexidade do sistema público e sua interação com uma diversidade de situações, ambientes e influências externas;

4. Os objetivos dos trabalhos para se utilizar a TOC foram diagnosticar e identificar limitações e possíveis pontos de melhoria para maior o desempenho de processos;

5. Os resultados das aplicações da TOC foram claramente positivos em todos os trabalhos analisados, sendo apontada a simplificação e melhoria do desempenho de processos, melhor gerenciamento de demandas; 
6. Como pontos positivos de se utilizar TOC no setor público foram identificados a simplificação dos processos administrativos e a facilitação do processo de tomada de decisão;

7. As dificuldades com a utilização da TOC manifestadas nesta pesquisa, foram as questões relacionadas ao tempo de implementação nos estudos; necessidade de investimentos financeiros, em alguns casos; e ainda a ansiedade da alta direção em relação aos resultados, antes do tempo planejado;

8. Há muitas atividades e funções envolvidas nos processos da administração pública e a falta de processo e instruções de trabalho padronizados, não estabelecem consistência para o resultado positivo com a implementação da TOC.

9. Como propostas de trabalhos futuros, pesquisas poderiam explorar a implementação completa do ciclo, de uma forma mais direta, no setor público.

\section{Discussão dos Resultados e Conclusões}

Este estudo mostra que a Teoria das Restrições pode ser vista como uma metodologia de gestão importante para a identificação dos pontos críticos que limitam os processos de produção de uma organização e não apenas para corrigir problemas de fabricação, mas também para mapear as situações e possíveis soluções, em qualquer área de atuação, inclusive no setor público.

Foram encontrados apenas 10 trabalhos com focos direcionados ao tema desta pesquisa, que é a administração púbica, sendo apresentada as áreas relacionadas aos serviços de saúde e as atividades de compras e contratações como as principais áreas do setor público que implementaram a metodologia da TOC e/ou uma de suas ferramentas na tentativa de melhoria dos processos de serviço.

O número de estudos da TOC relacionados ao setor público mostrou-se bastante oscilante, sendo os anos de maior publicação 2011, 2014 e 2017, com 3 publicações a cada ano; os demais anos entre 2009 e 2019 variaram entre 2 publicações a cada ano (2009, 2012 e 2018) e apenas 1 nos demais.

No que tange o setor público, esta revisão apresentou que a implementação da teoria das restrições tem funcionado de forma eficaz, impactando de maneira positiva as instituições nas quais a metodologia foi implementada.

Os estudos mostraram melhorias nos diversos segmentos em que foram utilizadas a TOC e/ou suas ferramentas; contudo, nos trabalhos consultados não foi apresentada uma estrutura completa de aplicação da teoria que possa ser replicada. 
O método mais utilizado nos estudos avaliados foi o Processo de Raciocínio, possivelmente por ser o método voltado diretamente para a eliminação dos efeitos indesejáveis que são observados.

Percebeu-se ainda que os trabalhos desenvolvidos exploraram mais a aplicação dos métodos SDBR e TP e o ciclo envolvendo cinco etapas para o gerenciamento da restrição apenas para a identificação do gargalo, não sendo demonstrado em nenhum deles ter havido a implementação do ciclo completo e seu reinício, a partir da resolução do primeiro ciclo. Portanto, trabalhos futuros poderiam explorar a implementação completa do ciclo, de uma forma mais direta, no setor público.

Pode-se concluir neste estudo que o serviço público pode ser analisado tendo em mente as teorias de gestão que são desenvolvidas pelo setor privado, contudo, há que se trabalhar em conjunto as resistências culturais e as regras e normativos que em alguns casos limitam as ações de gerenciamento, e ainda, o alinhamento político em todos os níveis hierárquicos correspondentes à área de implementação.

Diante do exposto, nota-se que o estudo contribui para a literatura por trazer um resgate dos trabalhos que abordaram a metodologia nas especificidades do serviço público, em um leque temporal expressivo, apresentando o comportamento da filosofia num ambiente dotado de peculiaridades que o torna diferente em relação ao setor privado. Tal contribuição é reforçada Medina e Pailaquilén (2010, p. 7) quando afirmam que "os pesquisadores precisam das Revisão Sistemática (RS) para resumir os dados existentes, refinar hipóteses, estimar tamanhos de amostra e ajudar a definir agendas de trabalho futuro considerados como seus sujeitos".

Do ponto de vista prático, a pesquisa destacou os benefícios da implementação da TOC em instituições públicas, setor este extremamente sensível à influências e vulnerabilidades advindas de interferência de fatores externos, políticos e descontinuidade administrativa, reafirmando a relevância da aplicação de seus métodos de melhoria para desenvolver os processos de serviços em qualquer área de atuação.

Dentre os benefícios apresentados, destaca-se a abordagem mais organizada às operações, que a ferramenta pode trazer, além do desenvolvimento de métodos de controle, execução e métricas de apoio a decisão; identificação de conflitos e as possibilidades de tratamento; a simplificação e melhoria do desempenho de processos; melhor gerenciamento de demandas, que por sua vez, promovem uma facilitação do processo de tomada de decisão.

Por fim, julga-se relevante o estudo para a sociedade, dada a possibilidade de descobertas capazes de trazer benefícios sociais gerais como um mecanismo de melhoramento contínuo para os processos e estratégias dos órgãos públicos, que por sua vez reflete no melhor atendimento aos anseios da sociedade.

Finalmente, considerado o pequeno número de trabalhos encontrados com relação ao tema estudado e ainda a complexidade do sistema público e sua interação com uma diversidade de situações, 
ambientes e influências externas, apontada nesta pesquisa, pode-se dizer que existe uma lacuna de conhecimento nessa área que deve ser suprido por meio de novas pesquisas, como por exemplo o gerenciamento da resistência cultural e balanceamento de carga de trabalho, com a implementação da ferramenta e ainda explorar a implementação completa do ciclo no setor público, em uma estrutura completa de aplicação da teoria que possa ser replicada.

\section{Referências}

Abdi, M., Hasanzadeh, \& A., Fani, A. (2014). Exploring the bottleneck of Iran's national innovation system by TOC Thinking Process. Technological and economic development of economy, v. 20, n. 4, p. 601-623. https://doi.org/10.3846/20294913.2014.880960

Ahmad, N., Ghani, N. A., \& Kamil, A. A. (2010). A framework for emergency department capacity planning using system dynamics approach and the Theory of Constraints philosophies. Proceedings - 24th European Conference on Modelling and Simulation, CECMS. Recuperado em 31 maio, 2019, de https://www.scopus.com/inward/record.uri?eid=2-s2.084857991406\&partner ID=40\&md5=f20f3f91e6114edaf35b5fe711a64ac9

Alfieri, A., Cantamessa, M., \& Montagna F. (2009). SOS Methodologies for the Definition of Lean Manufacturing Systems. Proceedings of the 13th IFAC Symposium on Information Control Problems in Manufacturing. Recuperado em 21 agosto, 2020, de https://reader.elsevier.com/reader/sd/pii/s1474667016339271?token=f4f57aa7818f05bf81b e8cc5f4ba7ca175781a7db84cffde78e3a080f9187284bda486cb408127282001e5c0a73eaffc

Amaral, T. M., \& Costa, A. P. C. (2014). Improving decision-making and management of hospital resources: An application of the PROMETHEE II method in an Emergency Department. Operations Research for Health Care, v. 3, n. 1, p. 1-6. https://doi.org/10.1016/j.orhc.2013.10.002

Andrade, G. C. de. (2012). Gestão Estratégica de Suprimento em uma Empresa do Setor Elétrico Brasileiro. Programa de Pós-graduação em Engenharia de Produção - COPPE. Universidade Federal do Rio de Janeiro.

Araújo, C. A. C. de (2004). Desenvolvimento e aplicação de um método para implementação de sistemas de produção enxuta utilizando os Processos de Raciocínio da Teoria das Restrições e o mapeamento do fluxo de valor. Escola de Engenharia de São Carlos. Universidade de São Paulo. São Paulo, SP, Brasil.

Aydinli, Ö. F., \& Ravesteijn, P. (2009). Business process improvement in a governmental shared Service Centre: a new approach to BPR. Recuperado em 31 maio, 2019, de https://www.researchgate.net/publication/46709521

Bardin, L. (2006). Análise de conteúdo. Análise de conteúdo (L. de A. Rego \& A. Pinheiro, Tradução). Lisboa: Edições 70.

Bauer, J.M., Vargas, A., Sellitto, M.A., Souza, M.C. \& Vaccaro, G.L. (2019), "The thinking process of the theory of constraints applied to public healthcare", Business Process Management Journal, Vol. 25 No. 7, pp. 1543-1563. https://doi.org/10.1108/BPMJ-06-2016-0118 
Bravo, A. L., \& Mariano, S. R. H. (2006). O papel dos sistemas de informação na modernização da gestão pública. Revista Eletrônica de Gestão Organizacional, v. 4, p. 69-77.

Cauter, L.V., Crompvoets, J., \& Voets, J. (2012). Improving intergovernmental information processes: in search of the appropriate management strategy.

Cavalcante, P., Camões M., Cunha, B., \& Severo W. (2017). Inovação no setor público: teoria, tendências e casos no Brasil. Instituto de Pesquisa Econômica Aplicada (IPEA). 266 p.

Chakravorty, S. S., \& Hales, D. N. (2016). Improving labour relations performance using a Simplified Drum Buffer Rope (S-DBR) technique. Production Planning \& Control, v. 27, n. 2, p. 102-113. https://doi.org/10.1080/09537287.2015.1079744

Constituição da República Federativa do Brasil de 1988. (2001). [Coleção Saraiva de Legislação]. (21a ed.). São Paulo: Saraiva.

Dutra, H. L., Santos, D. A., Lima, A. A., Soares, C. H. S., Quelhas, O. L. G. (2020). A Teoria das Restrições: Uma Revisão Sistemática Na Base Spell. Brazilian Journal of Development, Curitiba, v. 6, n. 1, p.1240-1251 jan. 2020. Recuperado em 15 jan, 2020, de https://www.brazilianjournals.com/index.php/BRJD/article/view/5996/5345

Fernandes, W. C. (2018). Modelagem de processos utilizando a teoria das restrições na divisão de transportes de uma universidade pública. Faculdade de Ciências e Tecnologia. Universidade Federal de Goiás. Aparecida de Goiânia, GO, Brasil.

Goldratt, E. M., \& Cox, J. (2002). A Meta. São Paulo: Nobel.

Gudelis, D., \& Guogis, A. (2011). Integrating public and business management: a model of interaction between public and private sectors. Theoretical Development, p. 1-9.

Hansen, H., \& Trifkovic, N. (2013). Systematic Reviews: Questions, Methods and Usage. Evaluation Study. Ministry of Foreign Affairs of Denmark: Copenhagen. Recuperado em 31 maio, 2019, de http://mpra.ub.uni-muenchen.de/47993/. https://doi.org/10.1590/S010411692010000400023

Hirtz, T., \& Guernaccini, P. (2015). Toward a model of performance measurement of output based on the Theory of Constraints. Studies in Managerial and Financial Accounting, v. 25, p. 117-137. https://doi.org/10.1108/s1479-3512(2012)0000025008

Ikeziri, L., Fiorini, P. D. C., \& Souza, F. (2016). Teoria das Restrições: evolução histórica e uma análise bibliométrica. Anais do XXIII Simpósio de Engenharia de Produção. Bauru, SP, Brasil.

Ikeziri, L., Souza, F. B., Grupta, M.C. \& Fiorini, P. C., (2018). Theory of constraints: review and bibliometric analysis. International Journal of Production Research. 57:15-16, 5068-5102, https://doi.org/10.1080/00207543.2018.1518602

Jesson, J. K., Matheson, L., \& Lacey, F. M. (2011). Doing your Literature Review: Traditional a Systematic Techniques. Los Angeles: Sage.

Kavishe, N., \& Chileshe, N. (2017). Joint Venture Housing Projects in Dar Es Salaam City: An Analysis of Challenges and Effectiveness In: Chan, P W and Neilson, C J (Eds) Proceeding of the 33rd Annual ARCOM Conference, 4-6 September 2017, Cambridge, UK, Association of Researchers 
in Construction Management, 144-153. Recuperado em 31 maio, 2019, de

https://www.researchgate.net/publication/319206387\%0AJoint

Knaggs, C., Pollard, S., \& Wang, W. L. (2012). Applying theory of constraints in administrative process: An experiment from the U.S. government. Proceeding of International Conference on Management Science and Engineering. Dallas, TX, USA. https://doi.org/10.1109/ICMSE.2012.6414447

Lacerda, D., \& Rodrigues, L. H. (2007). Compreensão, aprendizagem e Ação: A abordagem do Processo de Pensamento da Teoria das Restrições. Anais do SEGeT-Simpósio de Excelência em Gestão e Tecnologia. Resende, Rio de Janeiro, Brasil.

Lacerda, D. P., Rodrigues, L. H., \& Corcini Neto, S. L. H. (2011). Processo de pensamento da Teoria das Restrições: uma abordagem para compreensão, aprendizagem e ação sobre problemas complexos. Perspectivas em Gestão \& Conhecimento, 1(2), 59-76.

Lima, C. B. de, \& Souza, A. A. de Jr. (2018). Gestão da cadeia de suprimentos da Secretaria Municipal de Saúde de Manaus: Uma proposta de otimização do processo de aquisição de medicamentos. Revista de Administração de Roraima - RARR. V. 8, n. 2. Boa Vista, RR, Brasil. http://dx.doi.org/10.18227/2237-8057rarr.v8i2.4824

Luchi, O. A. (2006). Contribuição da Teoria das Restrições para o Processo de Compras das Organizações Militares do Exército Brasileiro. Anais do $30^{\circ}$ Encontro da ANPAD-EnANPAD. Salvador, BA, Brasil.

Mabin, V., Yee, J., Babington, S., Caldwell, V., \& Moore, R. (2017). Using the Theory of Constraints to resolve long-standing resource and service issues in a large public hospital. Health Systems, v. 6965, p. 1-20. https://doi.org/10.1080/20476965.2017.1403674

Marques, J., \& Cia, J. (1998). Teoria das Restrições e Contabilidade Gerencial. Revista de Administração de Empresas-RAE. v. 38, p. 230-249. https://doi.org/10.1080/20476965.2017.1403674

Medina, E. U.; Pailaquilén, R. M. B. A revisão sistemática e a sua relação com a prática baseada na evidência em saúde. Revista Latino-Americana de Enfermagem, Ribeirão Preto, v. 18, n. 4, p. 1- 8, jul./ago. 2010. Recuperado em 31 maio, 2019, de https://seer.ufrgs.br/Movimento/article/viewFile/41542/28358

Ministério do Planejamento, Orçamento e Gestão. Secretaria de Gestão Pública. (2005). Programa GESPÚBLICA, Modelo de Excelência em Gestão Pública.

Mishra, S., \& Sasmita, P. (2014). Applying Theory of Constraints to the Indian Administrative Services. Management and Labour Studies, 187-207. https://doi.org/10.1177/0258042X14558186

Nyakoe, V., \& Muturi, W. (2017). Effect of supplier selection criteria on performance of the procurement function of county governments in Kenya. International Journal of Social, III (II), 1725-1737. Recuperado em 28 junho, 2019, de https://www.ijssit.com/main/

Ochieng, O. C. (2018). Internal factors affecting efficiency of public procurement process in county governments In Kenya: a case of Kisumu County. International Journal of Business Management \& Finance, 1(42), 733-752. Recuperado em 28 junho, 2019, de https://www.serialpublishers.com 
Pacheco, A. D. de J., Luz, D. F. da, Rocha, E. A. M. da. Dornelles P. G., \& Antunes, J. A. V. Jr. (2012). Uma análise crítica entre a Teoria das Restrições e o Lean Manufacturing. Anais do XXXII Encontro Nacional de Engenharia de Produção. Recuperado em 28 junho, 2019, de http://www.abepro.org.br/biblioteca/enegep2012_tn_stp_157_913_19983.pdf

Rasheli, G. A., \& Mwagike, L. R. (2018). Institutional and regulatory constraints in managing procurement records: exploratory case of procuring entities in Tanzania. Records Management Journal. https://doi.org/10.1108/RMJ-02-2018-0005

Ren, Q., Luo, L., Yang, C., Ji, J., \& Gong, R. (2013). Applying the TOC five-step focusing process in surgical process. Proceedings of 10th International Conference on Service Systems and Service Management. https://doi.org/10.1109/ICSSSM.2013.6602658

Sadat, S., Carter, M. W. \& Golden B. (2013). Theory of constraints for publicly funded health systems Health Care Manag Sci 16:62-74. https://doi.org/10.1007/s10729-012-9208-9

Santos, J. G. dos. (2018). O controle de governança como boa prática na administração pública do Brasil: uma análise no ciclo de políticas públicas. Programa de Pós-Graduação em Planejamento e Governança Pública. Universidade Tecnológica Federal do Paraná. 196 p. Curitiba, PR, Brasil.

Slack, N., Chambers, S., \& JohnstonN, R. (2009). Administração da Produção. São Paulo: Atlas.

Souza, F. S. R. N., Schmitt, V. G. H., Pinto, A. F., \& Favero, C. G. (2016). Programa Netuno: Inovação para a melhoria da gestão na marinha do Brasil. Revista de Administração, Contabilidade e Economia, 15, 843-870. https://doi.org/1018593

Souza, F. B. (2005). Do OPT à Teoria das Restrições: avanços e mitos. Revista Produção, v. 15, n. 2, p. 184-197, Maio/Ago.

Tikk, J., \& Almann, A. (2011). Developments in public sector financial management in Estonia. Business and Economic Horizons, 5(2), 47-56. Recuperado em 28 junho, 2019, de http://www.academicpublishingplatforms.com\%OABEH

Tsitsakis, C., Polychronidou, P., \& Karasavvoglou, A. (2016). The Problem of Capacity Management in Greek Public Hospitals. EBEEC Proceedings of Conference the Economies of Balkan and Eastern Europe Countries in the Changed World, d, KnE Social Sciences, 414-420. https://doi.org/10.18502/kss.v1i2.676

Wasserbaur, R., \& Sakao, T. (2018). Analysing interplays between PSS business models and governmental policies towards a circular economy. In Procedia CIRP (Vol. 73, pp. 130-136). Elsevier B.V. https://doi.org/10.1016/j.procir.2018.04.004 